\title{
A TRANSPOSIÇÃO DIDÁTICA NO CURSO DE PEDAGOGIA DE UMA IES FEDERAL NA VISÃO DE SEUS PROFESSORES
}

\author{
M. T. SILVA, S. M. A. ISAIA e A. M. ROCHA \\ Universidade Federal de Santa Maria (UFSM) \\ marci.tasch@gmail.com
}

Artigo submetido em outubro/2013 e aceito em abril/2015

DOI: $10.15628 /$ holos.2015.1718

\section{RESUMO}

Este estudo é resultado de um trabalho de conclusão de curso, desenvolvido no Curso de Pedagogia da Universidade Federal de Santa Maria, que discute o processo da transposição didática dos professores formadores. Seus objetivos específicos foram analisar as aproximações/distanciamentos dos formadores em relação à transposição didática e sua compreensão com base nas estratégias de ensino-aprendizagem. Para a coleta de dados, foram realizadas entrevistas narrativas (CONNELY; CLANDININ, 1995) com docentes oriundos de diferentes áreas de conhecimento e que lecionam no Curso. A partir das análises sobre as falas docentes, foi possível percebermos que apesar dos docentes entrevistados não possuírem uma formação específica para a docência superior e não possuírem experiências prévias junto ao Curso de Pedagogia, eles se responsabilizam pelo processo formativo de seu alunos. Este fato é demonstrado em suas falas pela preocupação com a adaptação do universo de conhecimento trabalhado nas disciplinas do Curso, bem como com a preparação desses alunos para que possam transpor estes conhecimentos posteriormente para o contexto em que irão atuar.

PALAVRAS-CHAVE: Transposição Didática, Pedagogia, Áreas do conhecimento.

\section{DIDACTIC TRANSPOSITION IN A FEDERAL SCHOOL OF EDUCATION BASED ON THEIR PROFESSORS' VIEW}

\begin{abstract}
This study is based on a monograph, developed in the School of Education at the Federal University of Santa Maria, with the objective general to investigate how teacher educators recognize/realize the didactic transposition of their knowledge. And as specific aims, analyze the approaches/distances from professors regarding the didactic transposition and their understanding with based on the strategies of teachinglearning. For data collection, were conducted narrative
\end{abstract}

interviews (CONNELY; CLANDININ, 1995) with professors from different areas of knowledge and to teach on the college. From the analysis the professors speech, it was possible reflect on the knowledge developed in the School of Education, seeking possible initiate discussions about the challenge of offering a formation geared to the educational demands that await the today's student in their future performance.

KEYWORDS: Didactic transposition; Pedagogy; Areas of knowledge. 


\section{INTRODUÇÃO}

A formação docente no ensino superior é um tema atual, que tem sido foco de várias pesquisas. Estas investigam como os professores universitários constituem seus saberes didático pedagógicos, sendo que não há formação específica voltada para a profissão especificamente no contexto da educação superior. (IMBERNÓN, 2001; ISAIA, 2001; BOLZAN, 2006; MACIEL, 2009).

Os professores formadores possuem a responsabilidade de formar outros futuros professores e, muitas vezes, servem como modelos a serem seguidos pelos seus educandos em suas futuras atuações profissionais. Focando no contexto do Curso de Pedagogia, preocupa-nos a compreensão do conceito de Transposição Didática e as estratégias utilizadas no processo de ensino-aprendizagem pelos professores formadores. Contudo, nestes aspectos nos direcionamos a compreender a teoria que envolve o processo de ensino-aprendizagem nessa direção: a "teoria da Transposição Didática" (CHEVALLARD, 2005).

A Transposição Didática possibilita que o conhecimento construído em sala de aula possua uma linguagem adequada à compreensão dos estudantes, de forma que seja possível a apreensão deste conhecimento. Assim, cabe ao professor fazer a Transposição Didática de seu conhecimento específico, fazendo a seleção ou recorte dos conteúdos, hierarquizando, dividindo e reforçando alguns temas, organizando uma sequência e/ou buscando estratégias de ensino.

Desse modo, buscou-se a partir dessa investigação contribuir para a reflexão sobre a prática pedagógica de docentes formadores do Curso de Pedagogia, visto que independente da área de formação, todos os docentes em sua atuação necessitam de estratégias que auxiliem o processo de ensino-aprendizagem.

\section{A DOCÊNCIA NO ENSINO SUPERIOR}

A docência superior compreende as atividades desenvolvidas pelos professores, orientadas para a preparação de futuros profissionais. Tais atividades são alicerçadas não só em conhecimentos, saberes e fazeres, mas também em relações interpessoais, envolvendo uma série de valores, o que indica o fato da atividade docente não se esgotar na dimensão técnica, mas trata-se de um entrelaçamento entre as aprendizagens profissionais e as experiências pessoais (ISAIA e BOLZAN, 2006b). Assim, a docência superior apoia-se na interação de diferentes processos que respaldam o modo como os professores concebem o conhecer, o fazer, o ensinar, e o aprender, bem como o significado que dão a eles.

Neste sentido, é preciso refletir sobre quais são esses saberes necessários para a Transposição Didática no ensino superior, visto que estes sujeitos por falta de preparo profissional acabam constituindo sua professoralidade ${ }^{1}$ (BOLZAN e ISAIA, 2005), através do

\footnotetext{
1 Processo que se orienta para a constante apropriação de conhecimentos/saberes/fazeres próprios à área de atuação de cada profissão, implicando na sensibilidade do docente como pessoa e profissional em termos de atitudes e valores, tendo a reflexão como componente intrínseco ao processo de ensinar, de aprender, de formar-se e, consequentemente, de desenhar sua própria trajetória. (BOLZAN e ISAIA, 2005, 2007a, 2007b; BOLZAN e ISAIA, 2006)
} 
tempo e do espaço em que se encontram, por meio de teorias, práticas e experiências vinculadas à profissão.

Embora exista essa consciência a respeito da responsabilidade e compromisso dos professores pela formação dos acadêmicos, o exercício docente não é valorizado na Universidade. Isso se evidencia uma vez que a entrada em uma IES $^{2}$ e a progressão da carreira está relacionada à titulação e a produção científica. Dessa forma, os docentes na Universidade acabam focando seu trabalho mais para a pesquisa do que para o ensino, centrando-se em sua área de conhecimento específico, como se este domínio bastasse para o exercício da docência.

Segundo Bolzan e Isaia (2006), ser professor vai além do domínio da área de conhecimento, pois este exercício perpassa pelo menos três dimensões: o conhecimento científico, o conhecimento pedagógico e o conhecimento profissional. Sendo assim,

[...] é preciso considerar que a prática educativa do professor implica em possibilitar a passagem do conhecimento científico para o conhecimento acadêmico e deste para o profissional, ou seja, o exercício da transposição didática no ato educativo. A transposição didática assim configurada exige por parte do professor um domínio que envolve os conhecimentos de sua área, os conhecimentos pedagógicos a eles inerentes e os conhecimentos do campo profissional (BOLZAN e ISAIA, 2006, p. 494).

É essencial que o docente domine os conhecimentos de sua área específica de formação, porém precisa ter consciência da importância da dimensão pedagógica para a transposição de seu conhecimento. Esta envolve formas de conceber e desenvolver o ensino, proporcionando ao professor refletir sobre a sua prática, percebendo-se como mediador do processo de aprendizagem. A dimensão pedagógica oferece suportes para que ocorra uma interlocução entre a dimensão do conhecimento específico e a dimensão do conhecimento profissional, pois integra tanto o saber e o saber-fazer de determinada profissão específica. É através da dimensão pedagógica que o docente cria subsídios capazes de auxiliar o educando na elaboração de suas próprias estratégias de apropriação desses saberes, afim de que estes se tornem capazes de aplicar esse saber em diferentes situações em sua futura profissão, contribuindo deste modo para autonomia desses futuros profissionais.

Dessa forma, para que ocorra essa interlocução, é necessário que o docente apresente além de conhecimentos relacionados às diferentes profissões para as quais está formando os seus educandos, o domínio da dimensão pedagógica. Contudo, os estudos(ISAIA, 2001; PIMENTA e ANASTASIOU, 2002; BOLZAN, 2006; MACIEL, 2009) que vem sendo realizado ao longo dos tempos, apresentam indicadores de que a grande dificuldade apresentada pela maioria dos professores está relacionada ao fato de que a dimensão pedagógica não se faz presente na formação do professor de ensino superior. Este indicador aponta certa redundância, pois ao mesmo tempo em que estes docentes não foram preparados para o exercício de sua profissão, se espera deles a responsabilidade de preparar futuros educadores (IMBERNÓN, 2001). E é nesse sentido que este estudo buscou ouvir as vozes docentes com trajetórias formativas em cursos com características específicas distintas do Curso de Pedagogia, para analisarmos a forma como

\footnotetext{
${ }^{2}$ Instituição de Ensino Superior.
} 
entendem e realizam a transposição didática de seus conhecimentos específicos para um contexto diferente daquele em que foram formados.

\section{O CURSO DE PEDAGOGIA}

A Pedagogia definida por Libâneo (1998) é um campo de conhecimento específico da práxis educativa que ocorre na sociedade. Sendo assim, entende-se que pedagogo é o profissional que atua em várias instâncias da prática educativa, indireta ou diretamente vinculados aos processos de aquisição de saberes e modos de ação.

O Projeto Político Pedagógico do Curso de Pedagogia da UFSM (2006) segue a Resolução CNE/CP n1, de 15 de maio de 2006, apresentando como objetivo de atuação dos egressos do Curso, ser capaz de atuar em diferentes contextos, considerando a compatibilidade entre suas propostas e a realidade em que atua, tendo a pesquisa como guia de sua prática pedagógica. Desse modo, o pedagogo que se espera formar precisa dominar teorias e práticas de ensino, contemplando e interligando as diversas áreas de conhecimento, atuando assim, interdisciplinarmente. Contudo, essa relação interdisciplinar de certa forma decorre de um trabalho individual, uma vez que o conhecimento acadêmico ofertado aos estudantes ocorre de forma fragmentada, cabendo ao aluno reelaborar estes conhecimentos levando em conta o contexto escolar, interligando as áreas do saber. Essa questão nos remete novamente ao fato da falta de didatismo na formação dos docentes do ensino superior, que se de um modo não possuem uma formação pedagógica, atuam em um curso em que espera tal conduta de seus educandos.

A formação do docente do ensino superior reflete na sua docência, uma vez que oferecem aos seus alunos o conhecimento específico de sua área de domínio, sem estabelecer relações pedagógicas e estratégias didáticas para uma aprendizagem efetiva. No entanto, mais tarde, os mesmos cobram de seus alunos o estabelecimento de estratégias para o ensino das diversas áreas de conhecimentos específicos em suas futuras atuações. É nesse sentido que o professor universitário deve pensar sobre a sua formação e sobre o seu papel como mediador da aprendizagem, fugindo da concepção que se manteve por muitos anos, segundo Gil (2008), de que para ser professor bastaria um alto nível de conhecimento sobre determinado assunto.

Sabemos que não existem receitas para ser um "bom" professor, mas existem caminhos, e estes devem ser buscados em um processo de reflexão sobre a sua prática, de forma que ocorra uma autoformação, em que os saberes iniciais sejam constantemente reelaborados em confronto com as práticas vivenciadas.

\section{TRANSPOSIÇÃO: O PROCESSO DE TRANSFORMAÇÃO DOS SABERES}

O termo Transposição Didática foi introduzido pela primeira vez pelo sociólogo Michel Verret, em 1975, e depois aprofundado por Yves Chevallard, educador matemático. Chevallard em seu livro "A transposição didática: do saber sábio ao saber ensinado" (2005), afirma que a Transposição Didática é constituída por três partes interligadas: o saber do sábio, que é o saber elaborado pelos cientistas; o saber ensinar, relacionado à didática e a prática de mediação docente; e o saber ensinado, aquele aprendido pelo aluno por meio das transposições realizadas pelos cientistas e pelos professores. 
O conhecimento é resultado de uma necessidade da comunidade científica, que realiza pesquisas e estudos a fim de buscar respostas para algumas questões. Estas respostas geram conhecimentos, porém, para que esses conhecimentos possam ser divulgados e "consumidos", é preciso que sofram modificações para que possam ser aprendidos. A transposição didática é a ferramenta de ensino que possibilita que o conhecimento se adapte à capacidade cognitiva dos estudantes. Assim, cabe ao professor

[...] transformar este saber para os alunos, negociando com eles esta gestão, o papel que cada um deverá assumir, para que esse saber possa ser ensinado e aprendido. Neste sentido o professor imbui o saber a ser ensinado com seus aspectos particulares, subjetivos. (MATOS FILHO, 2008, p. 1193)

O processo de Transposição Didática vai ocorrer de acordo com a percepção que o docente possui sobre o funcionamento do ensino em determinado contexto, suas funções sociais, suas ações reflexivas acerca dos conteúdos, suas escolhas metodológicas, etc. Nesse sentido, é preciso que os docentes reflitam sobre suas estratégias de ensino na realização da transposição didática de forma que atendam às necessidades do ambiente educacional em que atuam, levando em consideração a complexidade e as possibilidades de aprendizagem de cada turma.

Dessa forma, a Transposição Didática está relacionada à ação entre professor, aluno e saber, pois é da relação existente entre essa tríade que vai ocorrer situações de ensino e aprendizagem. O professor precisa estar atento às transformações e adaptações que elabora sobre o seu saber, para que este não perca sua essência e possa ser aprendido pelos seus educandos.

\section{PERCURSO METODOLÓGICO}

A fim de investigar como os professores formadores realizam a Transposição Didática de seus conhecimentos nesse item iremos apresentar a construção do percurso metodológico, bem como o contexto pesquisado. A metodologia adotada foi de cunho qualitativo, que se caracteriza por aprofundar-se no significado das ações e relações humanas. (MINAYO, 1992).

A pesquisa envolveu três docentes formados em diferentes áreas de conhecimento que lecionam no Curso de Pedagogia Diurno da Universidade Federal de Santa Maria: Docente I Ciências Biológicas; Docente II - História e Docente III - Geografia.

O Curso de Pedagogia surgiu na década da criação da UFSM, em 1960. Atualmente, o Curso conta com em torno de 50 docentes e, 80 acadêmicos ingressando anualmente, localizando-se no Centro de Educação, Prédio 16, Campus I da UFSM, que está situada no coração do Rio Grande do Sul, mais precisamente na cidade de Santa Maria.

Dessa forma, foi desenvolvido uma pesquisa de campo (LAKATOS, 1985). Utilizamos como instrumento para a coleta de dados, entrevistas narrativas. Connelly e Clandinin apontam que: 
${ }^{3}$ La razón principal para el uso de la narrativa e la investigación educativa es que los seres humanos somos organismos contadores de historias, organismos que, individual y socialmente, vivimos vidas relatadas. El estúdio de la narrativa, por tanto, es el estúdio de la forma em que los seres humanos experimentamos el mundo. (1995, p.12).

Assim, foi proporcionado aos docentes que se distanciassem de suas profissões, transformando-as em objetos de reflexão, resgatando as suas vivências, suas práticas docentes e concepções.

Na fase posterior às entrevistas, realizou-se uma análise de conteúdo (Severino, 2007) para a interpretação das narrativas dos professores. O processo de interpretação das entrevistas transcritas exige um rigoroso cuidado, para que não ocorra a deturpação das ideias que o sujeito apresenta.

\section{CONCEPÇÃO DO PROFESSOR SOBRE A TRANSPOSIÇÃO DIDÁTICA}

O processo de Transposição Didática exige que o docente responsável pelo ensino de sua disciplina reconheça a significação e importância da transposição dos saberes, considerando a função social de sua área com o contexto em que está atuando, a fim de estabelecer uma compatibilização entre a sua área específica de conhecimento e o Curso de Pedagogia. É importante compreendermos qual é o entendimento dos professores formados em áreas específicas de conhecimento atuantes no Curso de Pedagogia sobre a teoria da transposição didática e, se demonstram preocupação em realizá-la em sua prática docente.

O Docente I, que possui formação inicial em Ciências biológicas e leciona a disciplina de Ciências e Educação no Curso de Pedagogia, identifica a Transposição Didática como:

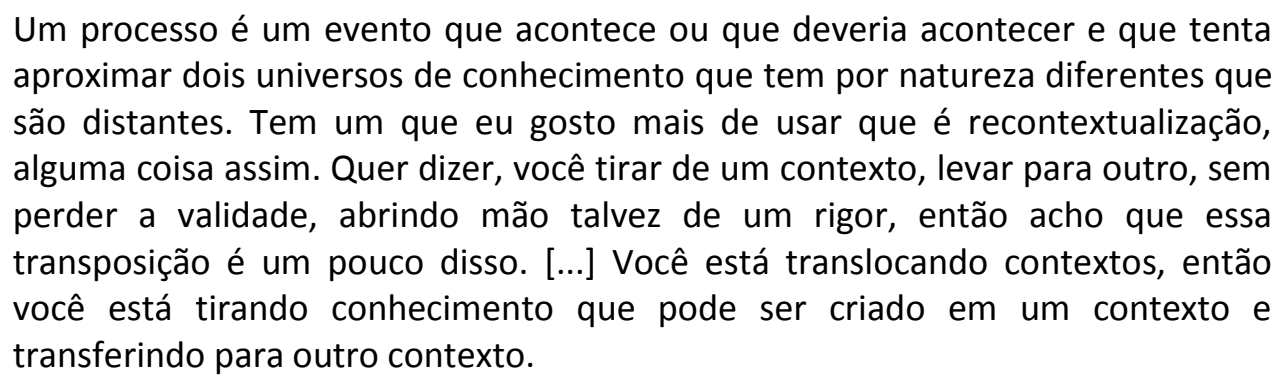

É possível identificarmos na narrativa que o Docente I tem consciência da distância existente entre o saber original e o saber a ensinar, considerando a importância de ambos os saberes, que apesar de corresponderem aos objetivos dos diferentes contextos onde é criado e comunicado, não perdem a sua identidade epistemológica.

Verificamos que o docente compreende o termo Transposição no sentido literal da palavra, como "uma troca de lugares" e, por esta razão afirma preferir identificar o processo utilizando o termo recontextualização. No entanto, Chevallard através de suas escritas deixa claro que o processo de Transposição Didática não deve ser compreendido no sentido restrito do

\footnotetext{
${ }^{3}$ A principal razão para o uso da narrativa e da pesquisa educacional é que os seres humanos são contadores de histórias, organismos que individual e socialmente, vivemos vidas contadas. O estudo da narrativa, portanto, é o estudo de como os seres humanos experimentam o mundo. [tradução nossa].
} 
termo, como apenas uma mudança de lugar. Esse processo envolve mais do que uma passagem, trata-se da transformação do saber mediante a necessidade desse saber ser comunicado e expandido.

Esse entendimento foi apresentado na narrativa do Docente II, que possui formação em História:

Entendo a ideia de que existem ciências referenciais sobre determinados conhecimentos e, essas ciências produzidas nas universidades é o estado puro da ciência e a importância que se tem é que nesse local se produz esse conhecimento, e esse conhecimento se produz essencialmente nesse espaço de pesquisa depois pode ser aproveitado pelas escolas, mas daí em um processo de transposição didática. Quer dizer, adaptando esse conhecimento às características dele, ou os conteúdos produzidos para atenderem as necessidades da escola. De certa forma simplificando ele, tornando mais acessível a um público.

Contudo, essa simplificação a que o docente II expõe ao final de sua fala, reconhecendo-a como parte do processo, não deve ser compreendida como depreciação do saber a ser ensinado, mas como reconhecimento de que cada saber possui a sua especificidade epistemológica.

Na fala do Docente III, que possui formação inicial em Geografia, percebemos que além do entendimento da teoria, o docente apresenta uma reflexão sobre as possibilidades e consequências possíveis desta transposição, demonstrando que se responsabiliza com o processo de ensino e aprendizagem, tendo um olhar para além desse conhecimento especifico.

Tem dois caminhos que eu percorro e entendo sobre a ideia da transposição. Essa relação de transpor a área para que seja compreendida em outro campo. Então a ideia primeiro é de relação, porque eu não entendo que os campos devam trabalhar separados, de forma desagregada, e geralmente é isso o que acontece. [...] Em um segundo momento a ideia da transposição no sentido de que é preciso que os conceitos, os saberes, a forma didática de operar da Geografia, o domínio científico próprio da Geografia, seja internalizada, apreendida e, de certa forma reorganizada na área de outro campo. [...] a transposição vai se dar nesse sentido, é uma forma pela qual o sujeito torna próprio, seu, mas sem perder a especificidade do domínio.

O processo de Transposição ao qual o docente se refere ultrapassa o significado de transmutação e adaptação, mas requer a compreensão dos contextos por onde este conhecimento perpassa. O primeiro contexto está diretamente ligado a produção deste conhecimento, ou seja, o conhecimento puro da área, compreensível aos professores/pesquisadores oriundos desta área específica. O segundo contexto diz respeito ao Curso de Pedagogia, onde este docente irá tentar desenvolver um trabalho utilizando o conhecimento de sua área, porém com uma linguagem diferente, uma vez que estes conhecimentos aqui terão outros objetivos e fins do que em seu contexto de origem. Pensando nisso, antes de realizar este processo de Transposição, o docente necessita conhecer e compreender outro campo para que possa realizar seu trabalho de ensino levando em conta as necessidades dessa outra área correlacionando com a sua de domínio. 


\section{ESTRATÉGIAS UTILIZADAS NO PROCESSO DE ENSINO-APRENDIZAGEM PELOS DOCENTES}

Para Isaia (2006), a docência integra tanto o saber e o saber-fazer próprios de uma profissão específica, quanto ao modo de ajudar ao aluno a construí-los, considerando sua dimensão formativa. Então, é importante ressaltar a importância do professor além de ter o domínio do conhecimento específico, saiba fazer uma transposição didática. Desse modo, além de ter que se apropriar do saber, o educador do ensino superior também tem que se apropriar do saber-fazer que ajude o acadêmico a construir e aplicar este saber, ultrapassando a transmissão mecânica e fragmentada de conhecimentos específicos. Vejamos os excertos a seguir:

Eu tenho que assumir que é importante o pedagogo saber ciências, porque é importante que ele trabalhe ciências com seus alunos. [...] o pedagogo, precisa ter uma boa formação em ciências, mas ele não é um cientista, não é um biólogo, ele tem outras coisas mais complexas para pensar, ou ele não é tão especializado quanto os meus alunos que vão dar aula da biologia, porque aí sim eles têm que saber muita biologia. [...]se a gente conseguir no Curso de Pedagogia apresentar o tipo de visão que a ciência tem de mundo, o jeito que ela opera, [...] Então o que eu aproveito da minha formação das áreas das ciências naturais, é mais o método, que não é um mas vários métodos, mas é mais o jeito de trabalhar do que os conteúdos conceituais enfim. [Docente I].

[...] eu não sou pedagogo, não tenho formação pedagógica, não fiz minha trajetória acadêmica na educação, minha trajetória é toda na história, portanto eu sou um historiador no sentido mais restrito do termo. E eu tento verificar as necessidades das turmas, que conteúdos, que realidades, que conceitos, que metodologias, que preocupações elas devem ter para operar essa área de conhecimento, mas aí considerando que elas têm demandas específicas que não são as demandas que os historiadores tem quando se produz os conhecimentos. Então eu tento realizar um trabalho atento às necessidades das turmas de Pedagogia e, a partir disso pensar em como que a história pode contribuir nesse processo de formação das futuras pedagogas, possibilitando a elas um entendimento geral de como se produz esse conhecimento histórico, quais os limites, características, enfim. [Docente II]

O Docente I utiliza como estratégia o foco nas formas de ensinar, demonstrando uma preocupação com a exploração das estratégias de ensino que seus alunos utilizarão em suas futuras atuações. Além disso, o Docente I assume uma postura de reconstrução de seu saber, no sentido em que busca e incentiva a construção de um novo entendimento dessa ciência por seus alunos.

Tanto o Docente I como o Docente II reconhecem a especificidade da formação dos pedagogos e apresentam como objetivo primordial a compreensão dos acadêmicos do funcionamento de suas áreas específicas. O Docente II ainda menciona a falta de formação pedagógica, indicando o reconhecimento de que sua formação o preparou para o domínio especifico de sua área, havendo uma ausência na preparação para a docência, ficando apenas no nível de qualificação e titulação. Há aí um paradoxo, ao mesmo tempo em que estes docentes não são preparados para o exercício desta profissão, pois suas formações centralizam os 
conteúdos, realizam esforços para oferecer esta formação para seus educandos, tornando-se formadores de formadores.

O Docente III desenvolve sua prática inter-relacionando dimensões que, segundo ele, são essenciais na formação de seus acadêmicos. Segundo Grillo e Enricone (1999, p. 10), "A ação didática do professor deve ter por objetivo enriquecer as competências e habilidades dos educandos para que possam adquirir domínio dos saberes escolares". Sendo assim, subentendemos que esta formação que o docente III busca desenvolver fornece bases para a formação de um sujeito autônomo, capaz de criar e recriar suas estratégias de ensino, produzir conhecimento e refletir sobre sua prática. Seguindo esta linha de pensamento Grillo e Enricone afirmam que

Não queremos modelos, receitas prontas, nem uma volta ao tecnicismo, mas que o docente reflita constantemente sobre suas aulas, faça questionamentos sobre a sua prática, torne o aluno partícipe de sua aprendizagem. Com este enfoque, o professor busca realizar uma investigação constante, aplicando a pesquisa na sala de aula. (1999, p. 11).

É por meio das estratégias de ensino/aprendizagem que se dá o processo de transposição didática, pois é através da adaptação, na transformação, na contextualização dos conteúdos que se realiza a efetiva aprendizagem.

A docência universitária possui um compromisso com a educação que vai além do ensino em sala de aula, compromisso e cobranças institucionais referentes a produção científica. Essa produção se dá de forma concomitante com o ensino e, infelizmente muitas vezes, de forma dicotômica. Demo (2001), defende que:

Sem pesquisa não há ensino. A ausência de pesquisa degrada o ensino a patamares típicos da reprodução imitativa. Entretanto, isto não pode levar ao extremo oposto, do professor que se quer apenas pesquisador, isolando-se no espaço da produção científica. Por vezes, há professores que se afastam do ensino, por estratégia, ou seja, porque do contrário não há tempo para pesquisa. Outros, porém, induzem à formação de uma casta, que passa a ver no ensino algo secundário e menor. Se a pesquisa é a razão do ensino, vale o reverso: o ensino é a razão da pesquisa, se não quisermos alimentar a ciência como prepotência a serviço de interesses particulares. Transmitir conhecimento deve fazer parte do mesmo ato de pesquisa, seja sob a ótica de dar aulas, seja como socialização do saber, seja como divulgação socialmente relevante (p. 51-52).

A pesquisa permite ao docente deixar de ser um mero transmissor, mas pensar e ser agente criador de seu trabalho. Significa incorporar um espírito de busca e atualização. Dessa forma, é importante que o professor realize sua pesquisa com objetivo de socialização, divulgando os seus achados em sala de aula, para despertar em seus alunos a postura de pesquisadores de suas futuras práticas. Para tanto:

O professor deve buscar a qualidade constantemente em sua formação, não se tornando um mero repassador de conhecimento. A atualização do profissional da educação amplia sua condição de orientar e direcionar aprendizagens que envolvem conhecimentos específicos e visão de mundo, ou seja, a formação integral do educando. É preciso ressaltar a importância da pesquisa como algo 
que norteará a vida acadêmica de futuros profissionais da educação para posteriormente fazerem a diferença. (Demo, 2001. p. 8).

Desse modo, é importante pensar sobre se os professores reconhecem a importância de suas pesquisas no processo de ensino e, se estes professores/pesquisadores pertencentes a outras áreas de ensino, sendo assim, pesquisadores destas, conseguem transpor estes conhecimentos para a área da Pedagogia e quais as repercussões resultantes desse trabalho.

Claro que eu uso os resultados das minhas pesquisas na Pedagogia, mas eu acho que o que eu consigo aproveitar melhor é o que pode ser chamado de método científico ou o jeito de tentar dar ciências para a Pedagogia, que eu acho que é o mais interessante. Porque se a gente conseguir no Curso de Pedagogia apresentar o tipo de visão que a ciência tem de mundo é mais importante do que eu ficar levando resultados das pesquisas de biologia. Essa transposição é quase que irreal, é muito distante, do que aquilo que é feito de uma pesquisa de ponta em uma área super específica da biologia para uma educação básica [...] Então, o que eu aproveito da minha formação das áreas das ciências naturais, é mais o método. [Docente I].

Verificamos na narrativa do docente I certa dificuldade de articulação de sua pesquisa entre as duas áreas de ensino: Ciências e Pedagogia. O docente ao mesmo tempo em que reconhece as peculiaridades da área pedagógica em suas narrativas já apresentadas anteriormente, estabelece o diálogo entre as áreas enfatizando na metodologia, mas considera que o Curso de Pedagogia tendo o foco dessa formação nos primeiros anos da educação básica, possui objetivos muito distantes dos conhecimentos específicos abordados por ele em suas pesquisas. No entanto, quando se faz pesquisa, esta deve ser realizada com a intencionalidade de contribuir qualitativamente no trabalho docente, sendo que o trabalho deste docente se realiza também no Curso de Pedagogia, a sua pesquisa deve ou deveria contribuir nesse contexto como possibilidade de ampliar/qualificar o processo de ensino/atualização/reflexão sobre a futura prática. Conforme Demo,

\begin{abstract}
Pesquisar, assim, é sempre também dialogar, no sentido específico de produzir conhecimento do outro para si e de si para o outro, dentro do contexto comunicativo, nunca do todo devassável e que sempre pode ir a pique. Pesquisa passa a ser ao mesmo tempo, método de comunicação, pois é mister construir de modo conveniente a comunicação cabível e adequar o conteúdo da comunicação, se for produtiva. Quem pesquisa tem o que comunicar. Quem não pesquisa assiste à comunicação dos outros. (2001, p. 39).
\end{abstract}

Nesse mesmo sentido, da relação do diálogo que a pesquisa deve estabelecer com a sociedade, a teoria de Chevallard (2005) apresenta a função da noosfera, que é a esfera norteadora da compatibilidade entre o saber produzido (sábio) e o saber ensinado. Essa relação pode ser refletida sobre a fala do docente I, quando ele justifica conseguir articular de forma mais significativa sua pesquisa com seus alunos graduandos em sua área específica de formação do que no Curso de Pedagogia, pelo fato de haver maior compatibilidade. De fato sua pesquisa tal qual como ocorre deve ser mais significativa no Curso de sua formação pelas duas ações ensino/pesquisa se tratarem de contextos praticamente com as mesmas especificidades. Para tanto, Chevallard defende em sua obra que o ato da pesquisa assim como gera conhecimento e que esses conhecimentos devem sofrer adaptações, o responsável ou um dos responsáveis pela 
compatibilização entre saber sábio e saber ensinado é o professor. Logo, é compromisso do professor adaptar este conhecimento conforme o contexto de seu trabalho, desconsiderando o fato desta compatibilidade já estar "dada" ou não.

É importante ressaltar que o Docente I considera importante, para além ou através da pesquisa, despertar no acadêmico a reflexão sobre a função social de sua área. Essa mesma preocupação pode ser percebida nas narrativas dos outros dois docentes.

\begin{abstract}
Eu trabalho com militares do RS no século XIX, então não é uma temática que eu possa incluir em qualquer aula na Pedagogia ou mesmo na História, porque é muito específica e pontual. A questão é que eu acho que não seja possível ser um bom professor de história, ou qualquer outra área específica se esse profissional não souber produzir o conhecimento. A partir do momento em que eu sei como se produz o conhecimento eu tenho possibilidades de repensar em como posso ensinar esse conhecimento que produzi para outras pessoas. Então ainda que eu não trabalhe com meu objeto de pesquisa em sala de aula, o exercício que eu desenvolvo com a pesquisa contribui de maneira significativa para o meu trabalho em sala de aula. [Docente II].

Não é que o momento de aula seja pra apresentar resultados de pesquisa que eu venho desenvolvendo, não. É tornar, esses resultados o momento do fazer pedagógico em aula com os alunos. Que eles possam perceber que aquilo que nós estamos desenvolvendo é resultado também de pesquisa, de investigação, de estudos, nesse sentido. Eu acho que não tem que separar essa relação da aula com pesquisa, porque a aula também é momento de pesquisa e aí é momento de não só trazer os resultados, mas momento de fazer com que se compreenda que aquilo que está se fazendo, se desenvolvendo é de resultado de pesquisa e vai resultar em outras pesquisas. [Docente III]
\end{abstract}

Os três docentes buscam através de seu trabalho contribuir para que esta geração de pedagogos ressignifiquem os conhecimentos de suas áreas, assumindo uma postura que vá além do domínio dos conhecimentos, mas que dê conta de estabelecer relações entre esses conhecimentos superando a fragmentação e a mera transmissão. Esse modelo de formação que se busca vai ao encontro com uma das dimensões da formação totalitária apontada por Masetto (1998) em que o sujeito, através das relações de reflexão e reconstrução que estabelece com os saberes, torna-se capaz de construir um significado para si próprio, repensando por meio disso a sua prática cotidiana, sendo capaz de realizar um trabalho interdisciplinar, ou seja, estabelecendo diálogo com diversas áreas de conhecimento, e contribuindo para uma educação que atenda as demandas atuais.

\title{
8 CONSIDERAÇÕES FINAIS
}

Ao traçarmos as considerações finais deste trabalho não temos a pretensão de esgotar aqui as reflexões inerentes ao tema.

Realizar este trabalho que teve como finalidade investigar a compreensão dos professores formadores do Curso de Pedagogia da Universidade Federal de Santa Maria (UFSM), sobre o processo de Transposição Didática de seus conhecimentos específicos, permitiu trazer para discussão a formação dos acadêmicos do Curso, bem como refletir sobre o processo de ensino e 
aprendizagem que envolve a tríade: professor (docente formado em áreas específicas do conhecimento), aluno (acadêmico do Curso de Pedagogia) e o saber (a disciplina curricular) (CHEVALLARD, 2005).

A Transposição Didática é a essência do ensinar (PERRENOUD, 1993; CHEVALLARD, 2005), é um conceito diretamente relacionado à dimensão pedagógica, visto que é por meio da adaptação/transformação que cada professor imprime ao seu conhecimento de domínio que vai resultar na compreensão e reconstrução dele pelos alunos em diferentes situações. A compreensão sobre a função e importância do processo de Transposição Didática foi apresentada nas narrativas dos docentes, demonstrando existir uma preocupação em atender as necessidades do ambiente educacional em que atuam.

O entendimento apresentado pelos professores sobre o processo de Transposição Didática em sua essência vai ao encontro da teoria criada por Chevallard, ao qual os docentes, mesmo apresentando algumas dificuldades no exercício dessa transposição, se colocam como responsáveis por promover a compatibilização entre o conhecimento ensinado e as necessidades do contexto em que atuam.

Percebemos, deste modo, que apesar dos docentes entrevistados não possuírem uma formação específica para a docência superior e não terem vínculos e experiências prévias junto ao Curso de Pedagogia, há uma responsabilização pelos docentes com o processo formativo de seu alunos. Isto é demonstrado em suas falas pela preocupação com a adaptação do universo de conhecimento trabalhado nas disciplinas do Curso, bem como com a preparação desses alunos para que possam transpor estes conhecimentos posteriormente em sua futura atuação.

Nas estratégias de ensino, assim como nos demais eixos, os docentes assumem a postura de reflexão sobre suas ações e, a partir disso, buscam ressignificar sua área de conhecimento considerando os interesses e necessidades referentes ao perfil do aluno que pretendem formar. Para tanto, para que o professor inicie o processo de Transposição Didática, deve ter consciência de que esta adaptação do saber não é algo pronto e acabado, mas algo mutável e passível de readaptações de acordo com seu tempo, local e interferências profissionais e pessoais. Cabe ao docente refletir sobre o seu cotidiano, questionar-se constantemente sobre o significado e o papel de seu trabalho para com a instituição, os acadêmicos, o Curso, as escolas e o sistema educacional como um todo.

É imprescindível levarmos em conta as dimensões constituintes do exercício docente (ISAIA e BOLZAN, 2006), onde o docente como formador de futuros formadores precisa considerar em seu processo de ensino a complexidade de seu trabalho que envolve conhecimentos específicos de sua área e o conhecimento profissional relacionando-os por meio da dimensão pedagógica.

Diante disso, entendemos que tais conceitos permeiam o processo de ensino/aprendizagem ofertado pelos docentes das áreas específicas de conhecimento no Curso de Pedagogia aos seus acadêmicos.

Este trabalho se propôs a provocar reflexões inerentes aos saberes desenvolvidos no Curso de Pedagogia, procurando desencadear possíveis discussões a cerca do desafio de se ofertar e produzir uma formação visando uma Transposição Didática reflexiva, colaborando com as demandas reais educacionais que aguardam o estudante de hoje, em sua futura atuação. 
Dessa forma, levando em conta a importância das diferentes áreas de conhecimento que compõe a grade curricular do Curso e, a falta de formação pedagógica dos docentes indicada por diversas pesquisas (PIMENTA, 2002; ISAIA 2006; BOLZAN 2006; MACIEL, 2009), consideramos ser importante iniciativas de criação de Cursos de formação continuada que contemplassem o processo reflexivo, priorizando a formação pedagógica, onde os docentes do curso pudessem confrontar seus conhecimentos na busca de novos saberes, inter-relacionando as diferentes áreas, buscando assim maior suporte para a sua prática docente.

\section{REFERÊNCIAS BIBLIOGRÁFICAS}

1. ALARCÃO, Isabel. Refletir na prática. Revista Nova Escola on-line. Ed. n. 154, Ago. 2002. Disponível em: http://novaescola.abril.com.br/index.htm?ed/154_ago02/html/fala_mestre>. Acesso em: 26 de dez. 2012.

2. BOLZAN. Doris Pires Vargas. Verbetes. In: CUNHA, M. I.; ISAIA, S. Professor da Educação Superior. In: MOROSINI, M. (Ed.). Enciclopédia de Pedagogia Universitária - Glossário- vol. 2. Brasília/ INEP, 2006, p. 358, 357, 368, 380.

3. BRASIL. Conselho Nacional de Educação. Resolução CNE/CP 01/2006, Institui Diretrizes Curriculares Nacionais para a Formação de Professores da Educação Básica, em nível superior, curso de licenciatura, de graduação plena. Diário Oficial da União, Brasília, DF, 15 mai. 2006.

4. CHEVALLARD, Yves. La transposición didáctica: Del saber sábio al saber enseñado. $3 \underline{a}$ ed. $2 \underline{a}$ reimp. Buenos Aires: Aique Grupo Editor, 2005.

5. CONNELLY y CLANDININ. Relatos de experiência e investigación narrativa. In: LARROSA; ARNAUS; FERRER et al. Déjame que te cuente. Barcelona: Alertes, 1995, p.11- 59.

6. DEMO, Pedro. Educação e qualidade. 6. ed. São Paulo: Papirus, 2001.

7. GIL, A. C. A didática do ensino superior. São Paulo: Atlas, 2008.

8. GRILLO, Marlene; ENRICONE, Délcia. Transposição didática: Uma criação ou recriação cotidiana. In: II ANPEDSUL. Curitiba: UFPR, 1999. Disponível em: http://www.portalanpedsul.com.br/home.php?link=anpedsul\&sublink=eventos_anteriores. Acesso em: 26 de dez. de 2012.

9. IMBERNON, Francisco. Formação docente e Profissional: Formar-se para a mudança e incerteza. São Paulo: Cortez, 2001.

10. ISAIA, Silvia Maria de Aguiar. Verbetes. In: CUNHA, M. I.; ISAIA, S. Professor da Educação Superior. In: MOROSINI, M. (Ed.). Enciclopédia de Pedagogia Universitária - Glossário- vol. 2. Brasília/ INEP, 2006.

11. _. Os movimentos da docência superior: construções possíveis nas diferentes áreas de conhecimento. Projeto de Pesquisa Institucional. CNPQ/PPGE/CE/UFSM, 2010 - 2013.

12. ISAIA, S.; BOLZAN, D.P.V. Elementos constitutivos do processo formativo de professores que atuam em licenciaturas. In: X Seminário Nacional Univérsitas. Porto Alegre: PUCRS/UFRGS, 2005.

13. _. Aprendizagem docente na educação superior: Construções e tessituras da professoralidade. Educação. Porto Alegre, 2006. 
14. _. Construção da profissão docente/professoralidade em debate: desafios para educação superior. In:XIII ENCONTRO NACIONAL DE DIDÁTICA E PRÁTICA DE ENSINOENDIPE.Anais. Recife, Universidade Federal de Pernambuco, 2006b.

15. LAKATOS, E. M.; MARCONI, M. A. Fundamentos de metodologia científica. São Paulo: Atlas, 1985.

16. LIBÂNEO, Jose Carlos. Pedagogia e Pedagogos, Para que? 1a ed. São Paulo: Cortez, 1998.

17. MACIEL, Adriana Moreira da Rocha. O processo formativo do professor no ensino superior: em busca de uma ambiência (trans)formativa. In: Pedagogia universitária: tecendo redes sobre a educação superior. ISAIA, Sílvia Maria de Aguiar; BOLZAN, Dóris Pires Vargas; MACIEL, Adriana Moreira da Rocha. Santa Maria: Editora da UFSM, 2009. p.63-77.

18. MASETTO, Marcos T. (org.) Docência na universidade. Campinas: Papirus, 1998.

19. MATOS FILHO, Maurício A. S. de. A transposição didática em chevallard: as deformações/transformações sofridas pelo conceito de função em sala de aula. In: Congresso Nacional De Educação/EDUCERE da Pucpr, 8. 2008, Curitiba. Anais...Curitiba: Pucpr, 2008. Disponível em:<www.pucpr.br/eventos/educere/educere2008/anais>. Acesso em: 10 nov. 2011.

20. MINAYO, M. C. de S. O desafio do conhecimento: pesquisa qualitativa em saúde. São Paulo, Hucitec-Abrasco, 1992.

21. PERRENOUD, P. Práticas pedagógicas, profissão docente e formação: perspectivas sociológicas. Lisboa: Dom Quixote, 1993.

22. PIMENTA, Selma Garrido (Org.). Pedagogia e pedagogos: caminhos e perspectivas. São Paulo: Cortez. 2002.

23. PIMENTA, Selma Garrido; ANASTASIOU, Léa das Graças Camargos. Docência no Ensino Superior. São Paulo: Cortez, 2010.

24. SEVERINO, Antônio Joaquim. Metodologia do trabalho científico. 23a ed. Ver. E atual. - São Paulo: Cortez, 2007.

25. UNIVERSIDADE FEDERAL DE SANTA MARIA, CENTRO DE EDUCAÇÃO. Projeto Político Pedagógico do Curso de Licenciatura em Pedagogia. Santa Maria: PROGRAD, 2006. Disponível em:http://w3.ufsm.br/pedagogia/ 